\title{
sciendo
}

DOI: 10.2478/orga-2021-0007

\section{Cyberloafing Research 1997-2019: A Citation-based Literature Review}

\author{
Jin-Nan WU ${ }^{1 \Phi}$, Mengmeng SONG ${ }^{1 \Phi}$, Joseph C. UGRIN², Lin LIU ${ }^{3}$, \\ Tingting $\mathrm{ZHU}^{1}$
}

\begin{abstract}
${ }^{1}$ Anhui University of Technology, School of Business, Ma'anshan, Anhui, China; wujinnanseu@aliyun.com (JW), 1500253842@qq.com (MS), 772142722@qq.com (TZ).

${ }^{2}$ University of Northern lowa, College of Business Administration, Cedar Falls; USA, joseph.ugrin@uni.edu (corresponding author)

${ }^{3}$ Anhui University of Technology, School of Management Science and Engineering, Ma'anshan Anhui, China; liulinahut@aliyun.com
\end{abstract}

\begin{abstract}
Background and purpose: The purpose of this study is to illustrate the evolution of cyberloafing research and identify the important papers in the development of cyberloafing knowledge.

Methodology: We identify a total of 116 research papers from the Web of Science (WOS) database that were published in top journals during 1997-2019. We performed citation analysis, co-citation analysis, and main path analysis to identify the most influential authors, countries, and institutions in the development of cyberloafing research, and graphically map the relationships between them.

Results: Cyberloafing research has progressed through three stages which we coin the emergent stage, the exploration stage, and the burgeoning stage. We also identify the relationships between articles and identify the distinct and significant knowledge streams, 16 influential papers that are seminal or highly sighted, and we identify the authors, institutions, and countries from which the research emerged. Researchers in the United States have produced the most research, followed by China, the United Kingdom, and Australia. The National University of Singapore produced the most research in our sample, and Vivian K. Lim of the National University of Singapore was the most influential author, anchored by her seminal piece on cyberloafing and organizational justice published in 2002. Conclusion: This study is, to our best knowledge, the first to examine the development of cyberloafing research using evidence-based analysis methods. It depicts the development of the cyberloafing literature and identifies significant streams that researchers can explore in the future. We conclude that future research should incorporate more direct measures of cyberloafing, examine individual consequences caused by too much cyberloafing, such as mental health.
\end{abstract}

Keywords: Cyberloafing, Citation analysis, Co-citation analysis, Main path analysis, Visualization

\section{Introduction}

The Internet has profoundly influenced and changed the way people live, work, and learn. It has brought about convenience and a new form of communication. In the workplace, it has also created new opportunities for employees to engage in non-work-related activities and sometimes non-productive activities. The concept of "cyberloafing" was first proposed in the mid-1990s (Kamins, 1995) and is regarded as a type of workplace deviance and asset misuse. However, at that time, the digitization of enterprises in countries around the world, especially in developing countries, was not widespread, and employees' cyberloaf-

Received: 14th December 2020; revised: 15th May 2021; accepted: 20th May 2021

$\Phi$ This author shares the first authorship. 
ing behaviors and the potential harm had not yet attracted the attention of researchers. Companies around the world gradually increased their investment in Internet resources in the early 2000s, and as the technology became more widespread in business enterprises, so did the potential for misuse and abuse. The problems caused by employees' misuse and abuse of the Internet started to attract the attention of academia soon after. Lim (2002) defined cyberloafing. She pointed out that cyberloafing involves employees who engage in non-work-related online activities during working hours, such as receiving or sending private emails or browsing the news. Lim (2002) developed a cyberloafing scale, which laid the foundation for future research in the field. Scholars have subsequently refined the definition and measurement of cyberloafing behavior (Anandarajan 2002; Blanchard and Henle 2008), identified antecedents at the individual (Blanchard and Henle 2008; Jia et al. 2013; O’Neill et al. 2014; Vitak et al. 2011 ) and organizational levels (Andreassen et al. 2014; Garrett and Danziger 2008; Henle and Blanchard 2008; Lim 2002), identified and explored potential outcomes (Coker 2013; Heflin et al. 2017; Meijman and Mulder 1998; Phillips 2006; Stoddart 2016; Syrek et al. 2017; Wu et al. 2018), and explored the effects at mechanisms aimed at controlling and deterring cyberloafing behavior (Ugrin and Pearson, 2013).

Research on cyberloafing has been conducted by scholars from all over the world, including the United States, China, Europe, and the Middle East, suggesting it is a global workplace phenomenon. There is still much to learn about cyberloafing, but researchers have made substantial progress over the last twenty years. Recently, Mercado et al. (2017) performed a meta-analysis to investigate the nomological network of cyberloafing. The results show the nature and valence of these non-work related cyberloafing behaviors. Their findings provide a synopsis of what we know about the antecedents of cyberloafing and provide a starting place for empirically grounded research in the future. However, to the best of our knowledge, no study has been conducted to summarize the influential authors, countries, and institutions engaged in cyberloafing research, or to identify the evolutionary path and important papers that have defined this stream of research over the past two decades. One reason for examining the evolution of the literature is the fact that the number of scientific papers on cyberloafing has become large and is continuously growing. That makes it an optimal topic for bibliometric analysis. Bibliometric analysis is a quantitative technique that can provide a macroscopic overview of large bodies of academic literature. It can be used to map the characteristics and the development of scientific output within a specific field of research and reveal the significant knowledge flows in the citation network (Jia et al., 2018).

This study aims to narrow the gaps in what we already know and define the pathway for future researchers to extend the body of knowledge by using bibliometric analy- sis. Specifically, social network analysis and visualization software such as CiteSpace, HistCite, and Pajek, were applied to perform social network and visualization analyses on the cooperation among authors, institutions, and countries in the field, and to quantitatively analyze the literature citation network and the main path between author connections in the field. As a result, this study identifies the influential authors, institutions, and countries of origin, and their degree of collaboration. It also reveals the path through which or knowledge about cyberloafing has evolved, which is useful from a historical perspective and from the perspective of researchers looking to extend or branch off from the existing streams. In the end, this study provides scholars with an understanding of the research progress on cyberloafing, and it identifies directions for future research.

\section{Article Selection and Methodology}

We conducted three literature searches on cyberloafing using information from the Web of Science (WOS). The SCI-EXPANDED (SCI) and SSCI databases served as the main data source to identify relevant articles for analysis. We used a number of subjects and titles in the three literature searches to avoid missing important articles due to the different names used for cyberloafing in the journals. Names for cyberloafing include cyberslacking, workplace internet deviance, and employee internet addiction, amongst other things. As a result, searches included subjects such as "cyberloaf*", "cyberslack*", "personal social media us*", and the titles were set included "personal internet us*", "personal web us*", "internet deviance", "Use in the workplace", "abuse in the workplace", "employee internet abuse", "employee internet addiction" et cetera. Considering that the concept of cyberloafing in the WOS database first appeared in 1997, we set the period for the three literature searches to 1997-2019 (The date of data collection is March 28, 2019). 76, 132, and 42 articles were collected from each literature search, respectively. We removed duplicate articles through manual screening and cross-validation, retaining 116 high-quality articles from the SCI and SSCI for analysis.

These articles are written by 255 authors, include 333 keywords, and 4487 references. They covered a total of 18 disciplines. Among them, psychology, business and economics, computer science, information science, library and information science, and telecommunication are the most common disciplines. Top journals such as Computers in Human Behavior, Cyberpsychology Behavior, Information \& Management, Behaviour \& Information Technology, Communications of the ACM, Cyberpsychology Behavior and Social Networking, Internet Research, Journal of Management Information Systems, Journal of Applied Psychology, and the Journal of Business Ethics published 
the most articles on cyberloafing.

We applied CiteSpace software to conduct visual and social network analysis on the authors, institutions, and countries associated with the 116 articles we identified. We used the HistCite citation analysis software to identify local citation scores (LCS), the number of times an article is cited in the current database. Also, we prepared a chronology of citations using a citation network analysis on the top 30 LCS articles. Finally, we used Pajek software, a sophisticated network analysis tool, to analyze the significant articles in the past 20 years and identify the main path in the relationships between them. We discuss this further below.

\section{Visualization Analysis}

\subsection{Publication distribution}

Through analyzing the chronological distribution of cyberloafing articles published from 1997 to 2019, and drawing a trend line on the volume of publications per given year, we can visualize the growth and development of the literature stream. The chronological distribution and the trend line showing the growth in the volume of publications is shown in Figure 1. According to the quadratic polynomial trend line, it can be seen that the trend line has an upward trend with the growth of the year, which shows that there has been rapid growth in the volume of research, and the growth continues to accelerate. The year 2002 was a turning point where the cyberloafing research left the emergent stage (average of one paper per year) and moved into the exploration stage. From 2002 to 2013, the annual number of publications grew and held steady at approximately four articles per year. After 2014, the average annual number of publications grew to nearly 12 significant articles per year, and we call this the burgeoning stage.

\subsection{Author visualization}

A total of 255 authors produced the 116 publications in our analysis, of which 226 (88.63\%) authors published just one paper. We used Price Law to determine the most productive authors (Price 1963). Price Law is a mathematical formula developed to analyze scientific growth and commonly used to determine the amount of contribution individuals make to a body of work. According to Price Law, the findings suggest that authors publishing two or more papers are productive in this field $(\mathrm{Mp}=0.749 * \sqrt{6} \approx 1.83)$. There are 29 productive authors in the cyberloafing field, and the top five most productive authors are Pablo Zoghbi-Manrique-de-Lara (6 articles), Anandarajan (5 articles), Lim (4 articles), and Simmers (3 articles).

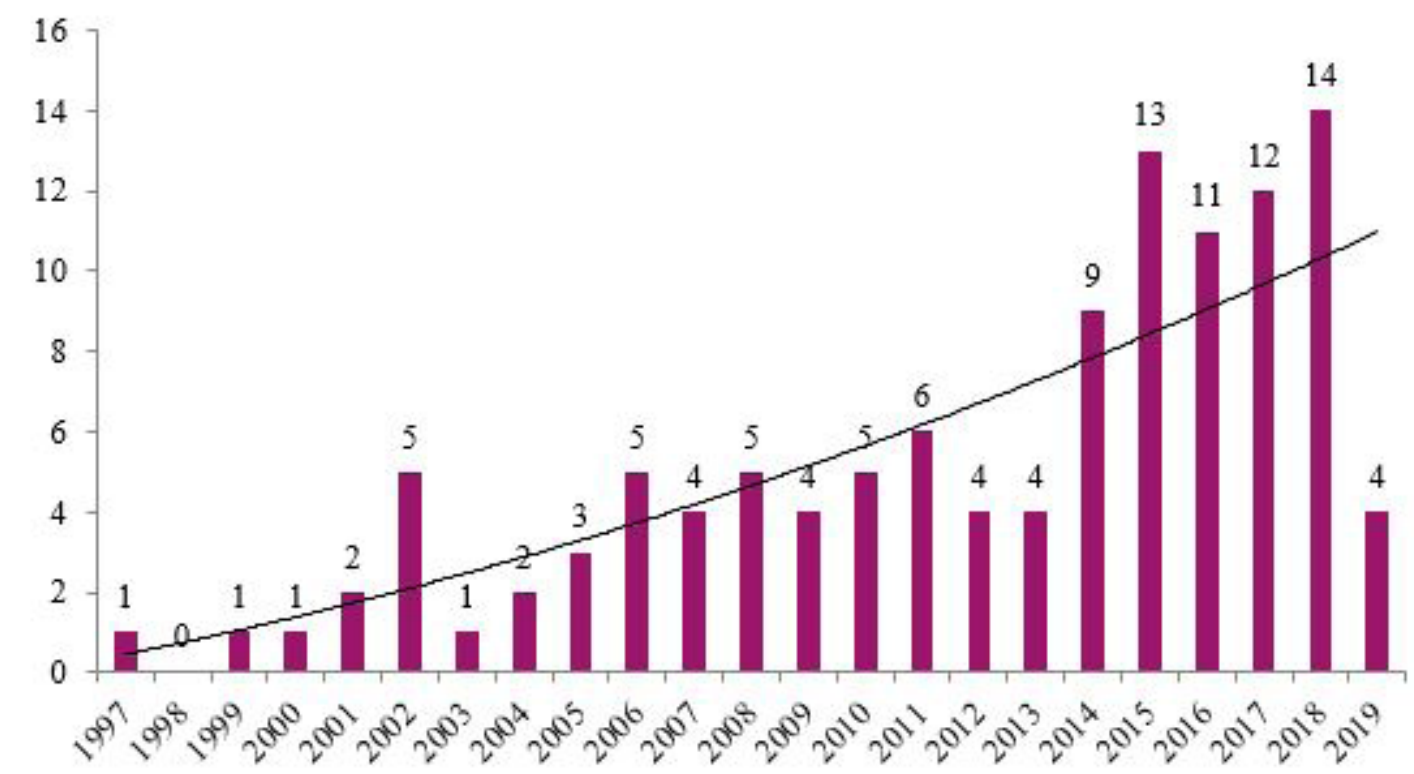

Note: The date of data collection is March 28, 2019. The curve is quadratic polynomial trend line of the number of paper published each year.

Figure 1: Annual distribution of cyberloafing papers (1997-2019) 
To further demonstrate the characteristics of the author's cooperation network, CiteSpace was used to perform a co-citation analysis according to the name of the author. The thresholds of $\mathrm{C}, \mathrm{CC}, \mathrm{CCV}$ in the first, middle and last three time periods are set to $(1,2,20),(2,3,20)$, $(2,3,20)$ to extract the data, that is, the beginning, middle and end of the data are assigned according to $\mathrm{C}, \mathrm{CC}$ and $\mathrm{CCV}$, where $\mathrm{C}$ represents the lowest citation or occurrence frequency, $\mathrm{CC}$ represents the co-occurrence or co-citation frequency of the time slice, and CCV represents the collinear rate or co-citation rate ( $\mathrm{Li}$ and $\mathrm{Chen}, 2017)$. The time slice was set to 1 year, and a map of the knowledge domain of the scientific cooperation network was drawn (Figure 2). The node in the figure 2 is the author's name, the size of the node represents the number of papers published by the author, the line reflects the strength of the cooperation relationship, and the color of the line represents the time of the first cooperation. The scientific cooperation network in this field has 57 nodes and 40 linkages. The network density is 0.0251 , indicating a relatively scattered academic cooperation network. The results show that Lim, Pablo Zoghbi-Manrique-de-Lara, Anandarajan, O'Neill, and Bock have the most significant impact on the citation network in this field.

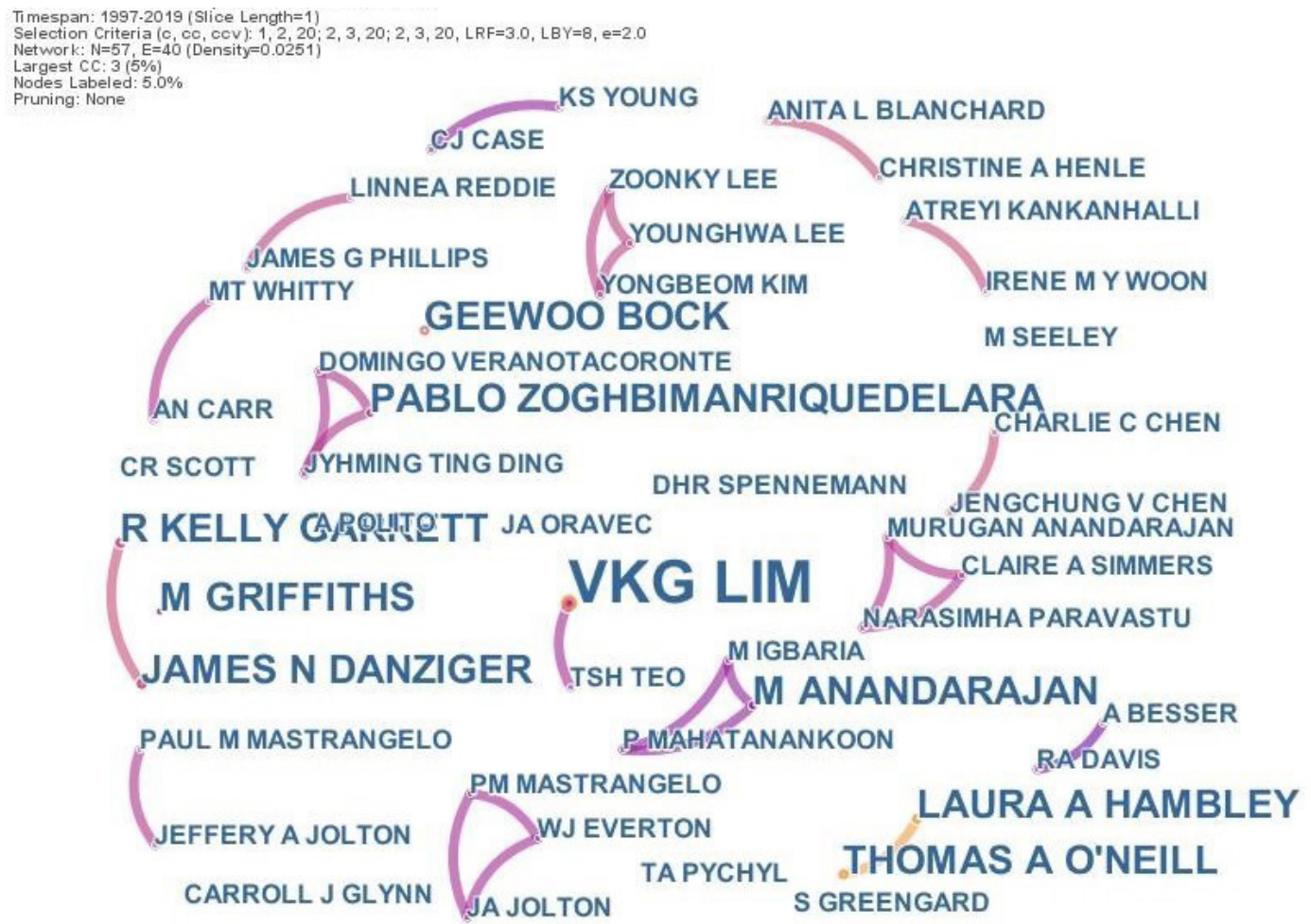

Figure 2: Author visualization

\subsection{Country visualization}

Betweenness centrality is an indicator of the status of individuals in a network (Freeman 1977). It can be used as a scientific measurement index to measure the importance of multiple indicators of scientific measurement units. The betweenness centrality of a node $(\geq 0.1)$ indicates that the point is a critical node ( $\mathrm{Li}$ and Chen, 2017). According to an analysis of authors' countries in CiteSpace, this study finds that American scholars published the most $(54,0.73)^{1}$
, accounting for $46.55 \%$ of the total publications; the second is China $(10,0.28)$ and the United Kingdom $(8,0.12)$, accounting for $8.62 \%$ and $6.90 \%$ respectively. Also, the betweenness centrality of Australia $(7,0.2)$ and Germany $(4,0.11)$ is higher than or equal to 0.1 , indicating those countries play important roles in the scientific cooperation network, albeit to a lesser degree than the United States, China, and United Kingdom respectively.

To analyze the cooperative relationship between the countries in this field further, the CiteSpace software was used to draw the map of the knowledge domain of the na-

\footnotetext{
${ }^{1}$ The front number is the frequency of occurrence, and the back number is the betweenness centrality of the country.
} 
tional cooperation network (Figure 3). The threshold is set to top 100 per slice, that is, the top 100 countries in each time slice are extracted. The node ring shows the distribution of the number of papers published by the country and the corresponding time. The color of the ring is consistent with the published time, the light color indicates the latest time and the dark color indicates the longer time. The thicker the ring, the more papers will be published at the corresponding time. The line between the two countries represents the cooperative relationship, while the single node indicates that this country has no cooperative relationship with other countries in the field of research.
The color of the line represents the time of the first cooperation between the two countries. The national cooperation network in this field consists of 27 nodes and 27 connections, and the network density is 0.0769 . Although the network density is not high, the cooperation between countries is significantly higher than that between authors. Among them, the United States is at the center of the international cooperation network in this field. Scholars from other major countries mainly cooperate with American researchers. China, Australia, and the United Kingdom are significant contributors. Chinese scholars, who are the second most productive, mainly conduct cooperative studies

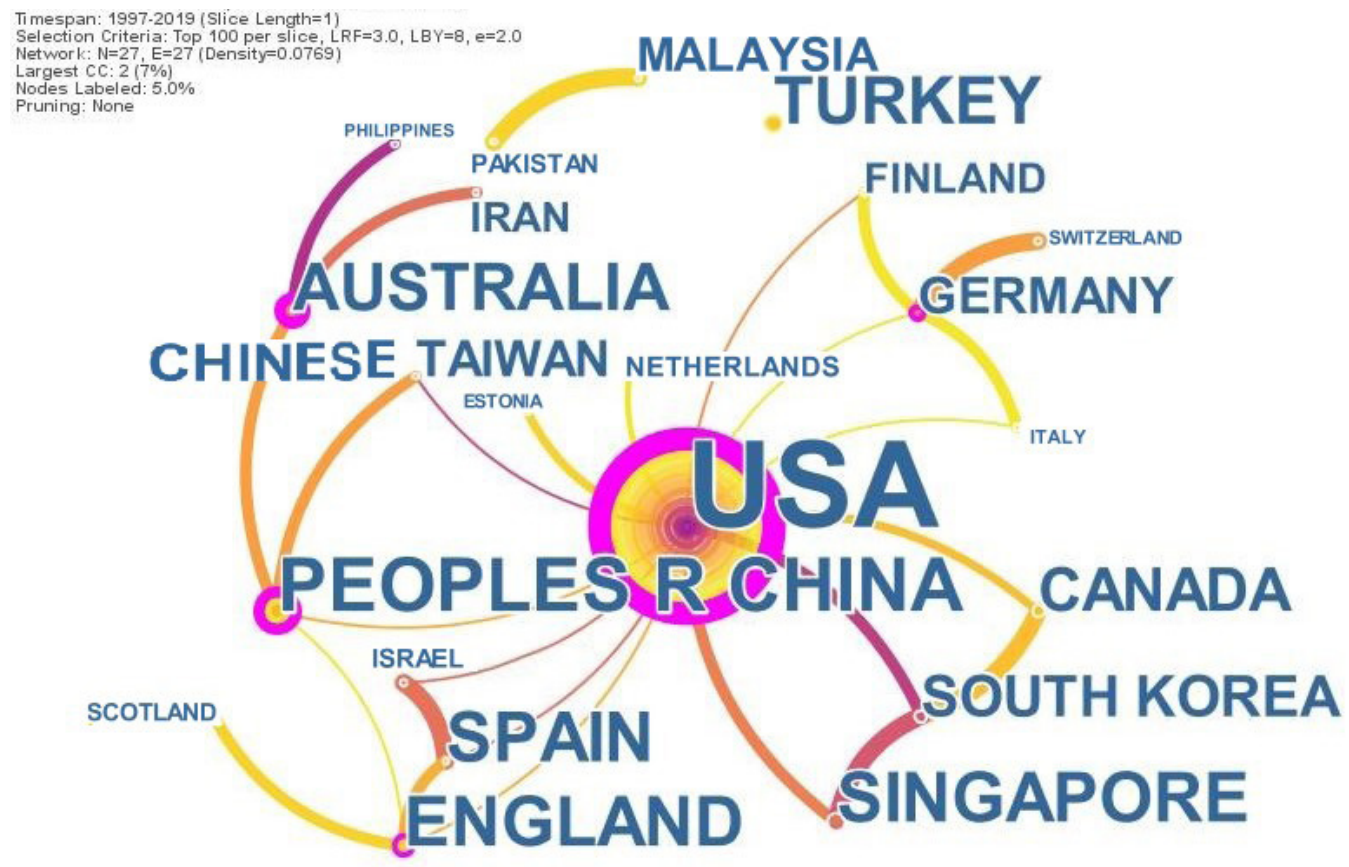

Figure 3: Countries visualization

with scholars from the United States, Australia, the United Kingdom, and Taiwan.

\subsection{Institution visualization}

We used CiteSpace software to draw a map of the institutional relationships in the knowledge domain and the (c, cc, ccv) thresholds were set to $(1,2,20),(1,3,20),(1,3,20)$. The institutional cooperation network shown in Figure 4 is composed of 163 nodes and 151 connections, and the network density is 0.0114 . The most active research institutions in this field are the National University of Singapore (6 articles), Drexel University (5 articles), Universidad Las Palmas (4 articles), Illinois State University (3 arti- cles), Southern Illinois University Carbondale (3 articles). Research amongst Chinese institutions was widely spread and includes the University of Science and Technology of China, Hefei University of Technology, Renmin University of China, Zhejiang Gongshang University and Anhui University of Technology. There are only 31 nodes in the author's cooperation network that have cooperative relationships, forming seven cooperative research groups, and one group has 14 nodes. These differences in nodes indicate that the research institutions in this field are scattered and there is a lack of highly cohesive academic cooperative groups. 


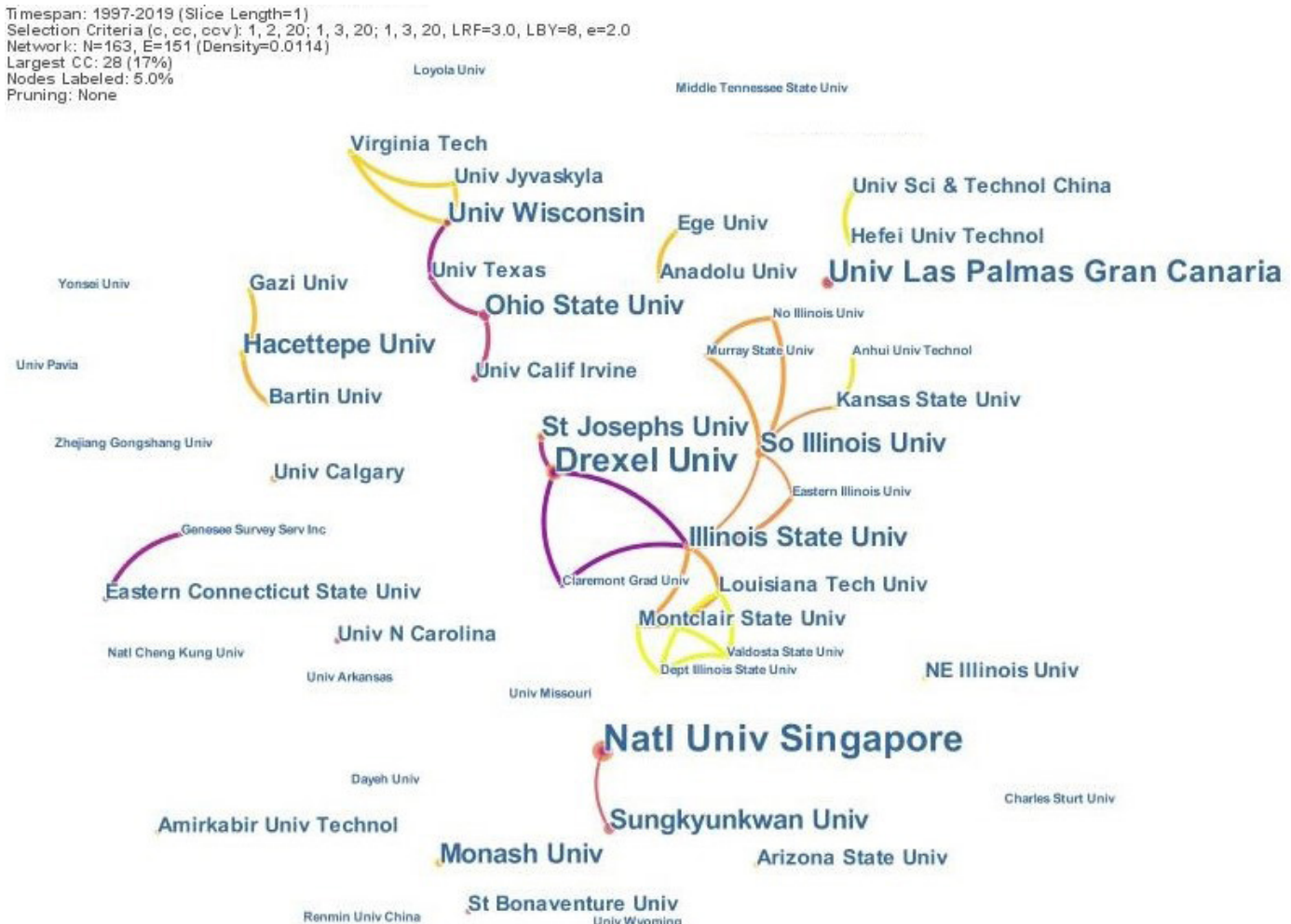

Figure 4: Institution Visualization

\section{Main paths}

\subsection{Citation Network Analysis}

Citation network analysis refers to studying the context of knowledge dissemination and the distribution of the characteristics of the citations by analyzing the relationship between article citations. This study selects the top 30 cited articles and uses the HistCite software to generate the chronology of citations ${ }^{2}$. The citations shown in Figure 5 are arranged in chronological order from top to bottom. The size of the ellipse indicates how many times the article has been cited. The number shown in each node indicates the serial number of the article in HistCite. The line with the arrow indicates the citation relationship between nodes. When looking at the direction of the arrow, the citing article points to the cited article. There are a total of 30 nodes and 110 connections in the chronology. The maximum LCS is 56 and the minimum is 7. Among them, nodes $7,9,16,28,41,46$, and 57 are the core nodes. The articles represented by these nodes are the most cited articles with a high citation frequency. These articles are important for the transfer of knowledge on cyberloafing. They play critical roles in studying cyberloafing and have been widely cited by other scholars in later research.

Important papers started with LAVOIE and PYCHYL (node 4) and BLOCK (node 5). Lavoie and Pychyl (2001) surveyed North American employees and they found that cyberloafing is related to procrastination and negative emotions. Block (2001) proposed that cyberloafing is a new and unique management challenge caused by new technologies. He analyzed cyberloafing from the perspective of ethics, supervision, loss of productivity, and public policy. Lim (2002) (node 9) formally proposed the concept of cyberloafing, and developed a widely used measurement tool to test the propensity to cyberloaf, and laid a theoretical foundation for subsequent empirical research. Most of the subsequent studies (including Key nodes such as $16,28,41$, and 43 ) stem from node 9 .

\subsection{Main path analysis}

Main path analysis is a quantitative method for identifying critical paths and key nodes. It calculates all paths

\footnotetext{
${ }^{2}$ We chose 30 articles because if the number of articles involved in the chronology of citations is too large, the graphics would be too complicated, and the overall visualization will be poor. However, if the number of articles involved is too small, it would be difficult to find the knowledge evolution path.
} 
from the starting point to the terminal point. That is, starting from the earliest known reference or literature that does not cite other research, the method calculates all the paths leading to the latest research. The traversal weight of each edge is calculated after the paths are identified. The traversal weight reflects the importance of each citation in the overall development of the research. This research uses Pajek $^{3}$, a complex social network analysis tool, to map the main path of knowledge evolution. The visual presentation of the main path makes it easier to highlight the key articles and citation relationships in the research development process.

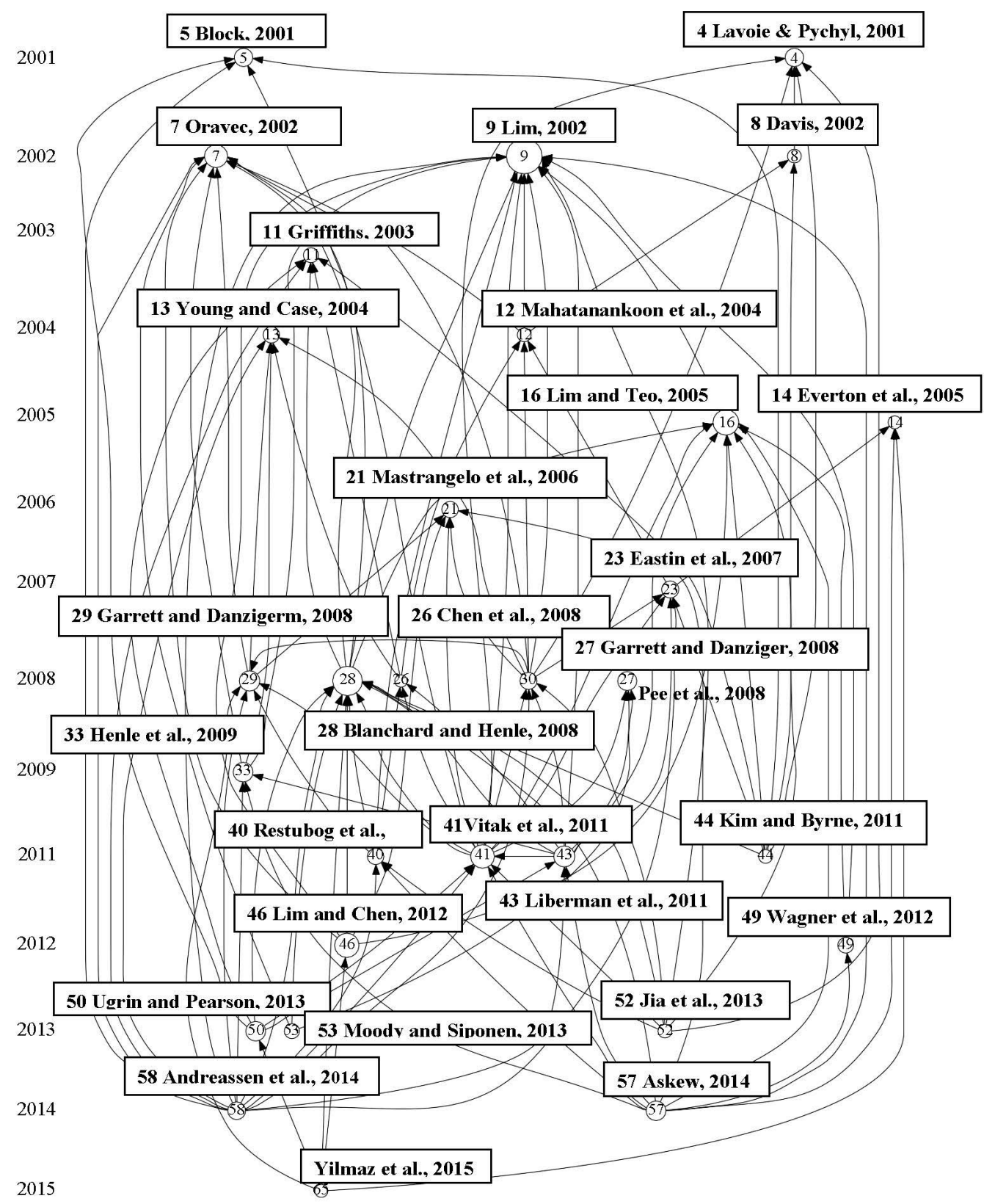

Figure 5: Citation Chronology

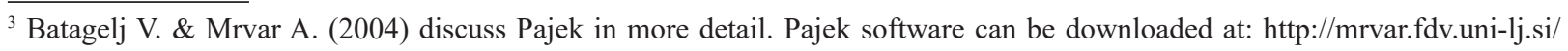
pajek/. 
The path counting method (SPC) proposed by Batagelj (2003) was used to calculate the traversal weight of the edges. The global main path graph and regional main path graph are presented in Figure 6 and Figure 7, respectively. Among them, the label of each node is composed of the first author's last name and publication year. The arrow reflects the direction of the knowledge flow, and the thickness of the line reflects the size of the SPC value. The thicker the line, the more significant it is in the main path. Figures 6 and 7 show that, except for the three nodes of Lavoie and Pychyl (2001), Davis et al. (2002) and Oravec (2002), the regional main path is exactly the same as the global main path, indicating that these 16 papers play key roles in the evolution of knowledge in this field.
Table 1 summarizes the 16 articles appearing on both the regional main path and the global main path. These articles constitute the central structure of the network and play essential roles in the flow of knowledge in this field. Among them, Akbulut (No. 79, 93 first author), Anandarajan (No. 6 first author, No. 12 second author), Ugrin (No. 50 first author, No. 104 third author), and Donmez (No. 79 third author, No. 93 second author) appeared twice in the main path. These authors have played important roles in the diffusion of knowledge. As aforementioned, Lim (2002) is a particularly important paper that has played a role in setting the stage for future research, namely through the development of a tool for measuring peoples' propensity to cyberloaf.

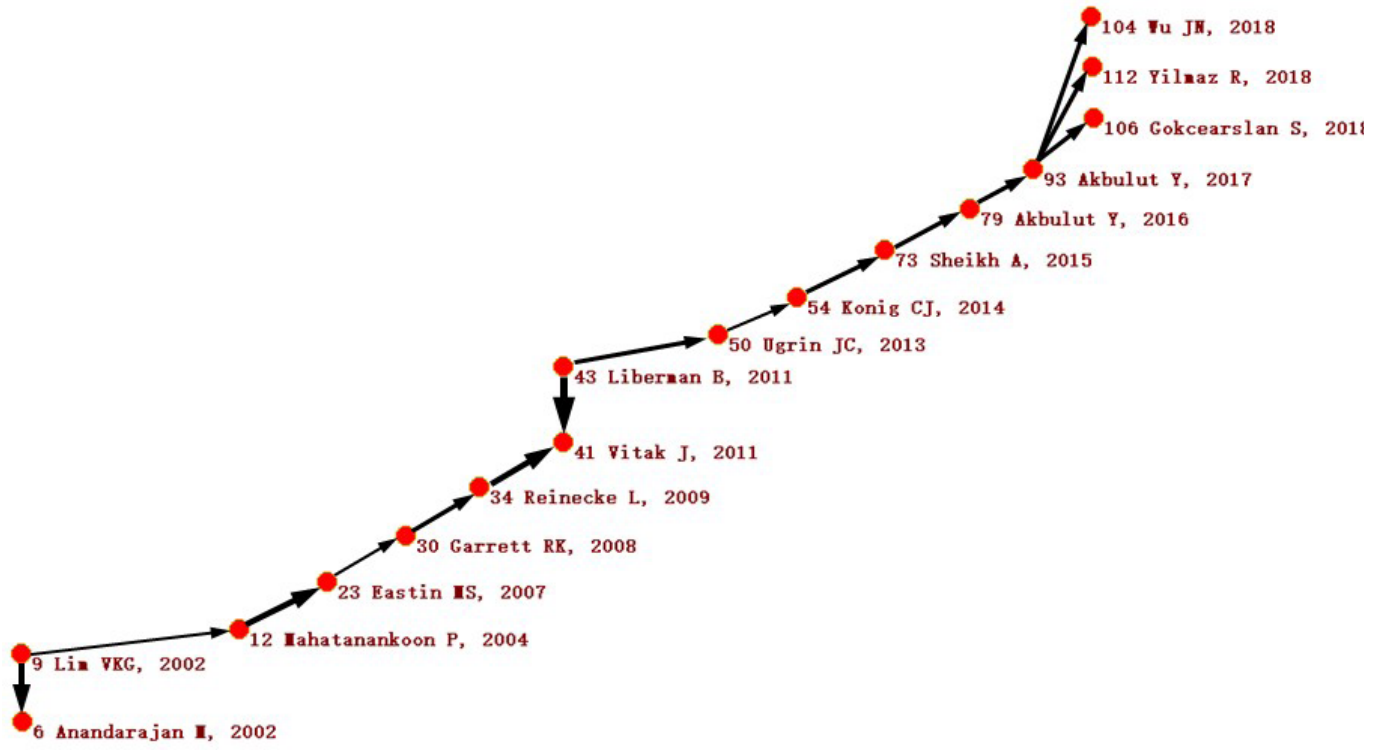

Figure 6: Global main path

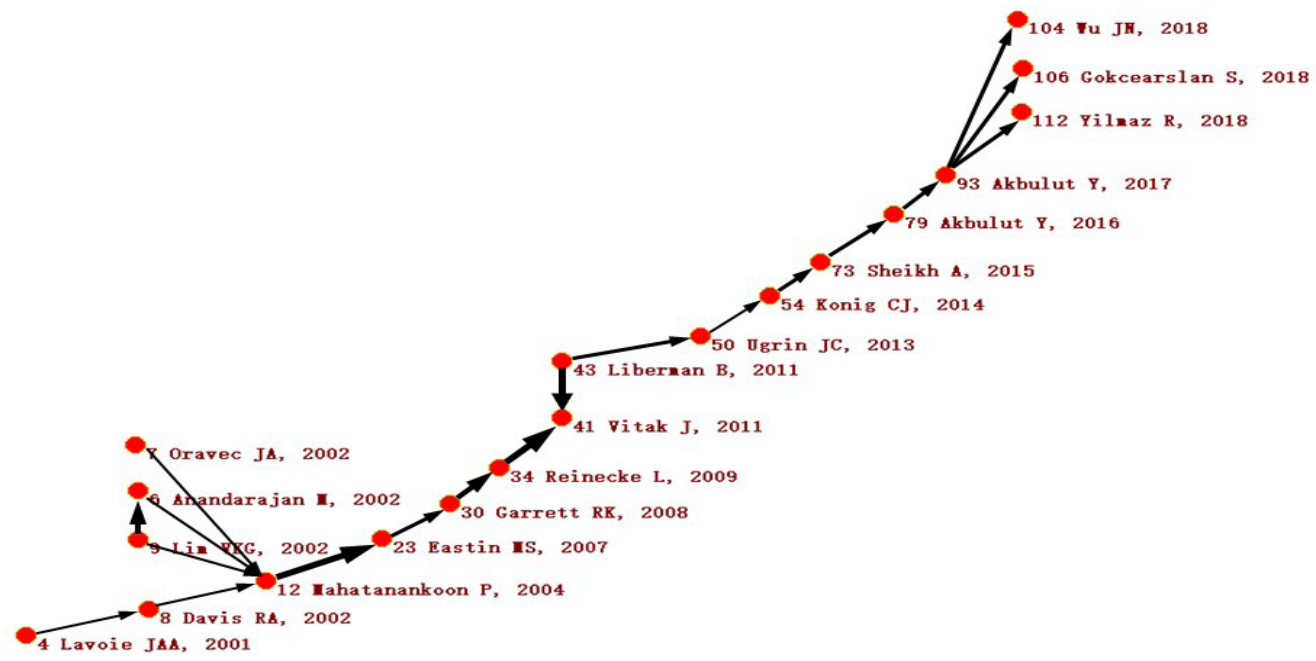

Figure 7: Local main path 
Table 1: Important articles appearing on both global (figure 6) and local (figure 7) main paths

\begin{tabular}{|c|c|c|c|c|c|}
\hline No. & Title & First author & Year & LCS & GCS \\
\hline 6 & Internet abuse in the workplace & Anandarajan M & 2002 & 6 & 19 \\
\hline 9 & $\begin{array}{l}\text { The IT way of loafing on the job: cyberloafing, neutralizing and organiza- } \\
\text { tional justice }\end{array}$ & Lim VKG & 2002 & 56 & 213 \\
\hline 12 & Development of a measure of personal web usage in the workplace & Mahatanankoon P & 2004 & 9 & 26 \\
\hline 23 & Psychology of communication technology use in the workplace & Eastin MS & 2007 & 13 & 21 \\
\hline 30 & $\begin{array}{l}\text { Disaffection or expected outcomes: Understanding personal Internet } \\
\text { use during work }\end{array}$ & Garrett RK & 2008 & 13 & 33 \\
\hline 34 & $\begin{array}{l}\text { Games at Work: The Recreational Use of Computer Games During } \\
\text { Working Hours }\end{array}$ & Reinecke L & 2009 & 5 & 32 \\
\hline 41 & Personal Internet use at work: Understanding cyberslacking & Vitak J & 2011 & 25 & 78 \\
\hline 43 & $\begin{array}{l}\text { Employee job attitudes and organizational characteristics as predictors } \\
\text { of cyberloafing }\end{array}$ & Liberman B & 2011 & 20 & 42 \\
\hline 50 & The effects of sanctions and stigmas on cyberloafing & Ugrin JC & 2013 & 17 & 35 \\
\hline 54 & $\begin{array}{l}\text { Exploring the positive side of personal internet use at work: Does it help } \\
\text { in managing the border between work and nonwork? }\end{array}$ & König CJ & 2014 & 7 & 11 \\
\hline 73 & $\begin{array}{l}\text { The antecedents of cyberloafing: A case study in an Iranian copper } \\
\text { industry }\end{array}$ & Sheikh A & 2015 & 5 & 14 \\
\hline 79 & $\begin{array}{l}\text { In search of a measure to investigate cyberloafing in educational set- } \\
\text { tings }\end{array}$ & Akbulut $Y$ & 2016 & 5 & 11 \\
\hline 93 & Cyberloafing and social desirability bias among students and employees & Akbulut Y & 2017 & 3 & 6 \\
\hline 104 & $\begin{array}{l}\text { Student Cyberloafing In and Out of the Classroom in China and the } \\
\text { Relationship with Student Performance }\end{array}$ & Wu J & 2018 & 0 & 0 \\
\hline 106 & $\begin{array}{l}\text { Smartphone addiction, cyberloafing, stress and social support among } \\
\text { university students: A path analysis }\end{array}$ & Gokcearslan S & 2018 & 0 & 0 \\
\hline 112 & $\begin{array}{l}\text { Cyberloafing in IT classrooms: exploring the role of the psycho-social } \\
\text { environment in the classroom, attitude to computers and computing } \\
\text { courses, motivation and learning strategies }\end{array}$ & Yilmaz R & 2018 & 0 & 0 \\
\hline
\end{tabular}

\section{Literature Summary}

We split the literature into three stages to depict the lifecycle. The three stages are the emergent stage (1997$2001)$, the exploration stage $(2002-2013)$, and the burgeoning stage $(2014$ - present). The earliest literature tends to be exploratory and examines a wide range of factors. We refer to this as the Emergent stage (1997-2001). Cyberloafing is defined during this stage. Research during the emergent stage takes a high-level view of the content and characteristics of cyberloafing and explores the symptoms and intervention measures. There are four important articles in the stage. The first article appearing in our literature review, Polito (1997), defined cyberloafing, proposed causes and consequences, suggested that such behavior can be controlled. Lavoie and Pychyl (2001) explored the relationship between cyberloafing and need for entertainment, stress relief, and feelings of negative emotions. Block (2001) has studied the relationship between cyberloafing and perceptions of the legality and morality of engaging in it. Greengard (2000) outlined hidden costs caused by cyberloafing.

The Exploration stage (2002-2013), analyzes cyberloafing as a workplace behavior in more detail, including its causes, benefits and consequences, and control mechanisms. The research is more theoretical and robust. Seminal articles in this stage include Lim (2002), who created a tool for measuring peoples' propensity to cyberloaf, along with Blanchard and Henle (2008) who proposed a structural model of cyberloafing which laid a theoretical 
foundation for subsequent empirical research. Blanchard and Henle (2008) and Vitak et al. (2011) identified the antecedents of cyberloafing from the perspective of individual characteristics. They found that males, individuals with controlled personalities, young people, ethnic minorities, and individuals who are proficient at using computers are more likely to engage in cyberloafing behavior than others. Jia (2013) suggested that emotional state affects individual cyberloafing behaviors as individuals who have stable emotions are less likely to cyberloaf than neurotic individuals. Other research finds that employees with negative emotions are more likely to reduce emotional stress through cyberloafing (Moody and Siponen 2013). Vitak et al. (2011) also looked at the effects of job characteristics and found that the creativity of peoples' work affects their propensity to cyberloaf. They found that the simpler peoples' work and the higher the repetition, the more they are to engage in cyberloafing. Studies by Henle and Blanchard (2008), Garrett and Danziger (2010), and Reinecke (2009) have also shown that work stress and work fatigue can affect cyberloafing behavior. That is, employees engage in cyberloafing as a recovery experience when they encounter job stress or fatigue. Blanchard and Henle (2008) also found that the more frequently employees use the Internet while at work, the more likely they are to cyberloaf. Lim(2002), Garrett and Danziger (2010), Reinecke (2009) and Ugrin and Pearson (2013) investigated cyberloafing from the context of organizational justice, social support, and the degree of control, finding that external consequences, social stigmas, and other neutralizing efforts influence peoples' propensity to cyberloaf.

During this exploratory period, most scholars assumed and investigated the adverse effects of cyberloafing. For example, cyberloafing has been found to reduce engagement, waste time and reduce productivity (Griffiths 2011; Liberman et al. 2011). However, Mahatanankoon et al. (2004) believed that employees' cyberloafing does not decrease their work efficiency. A possibility that is explored in later research.

The volume of research on cyberloafing has progressively increased since 2014, and we refer to this most recent state as the Burgeoning stage (2014 to present). The recent research continues to focus on measurement and antecedents (e.g. Akbulut et al. 2016; Sheikh et al. 2015), but two prominent new features have emerged. One is the extension of the research from the organizational context to the educational context, and the other is the positive effects of cyberloafing. Akbulut et al. (2017) compared the differences in the level of cyberloafing between students and employees. Akbulut et al. (2016) developed a measurement tool for cyberloafing among students and compared the differences in the level of cyberloafing between male and female students. Gökçearslan et al. (2018) examined the impact of social support and stressors on the undergraduate student's cyberloafing behavior. Y1lmaz and
Yurdugül (2018) studied the influence of college students' attitudes towards computers, psychosocial perceptions, and learning strategies on cyberloafing in the classroom. König and Guardia (2014) explored the positive effects of cyberloafing and found that cyberloafing helps employees manage the blurring of the lines between work and nonwork time. Wu et al. (2018) analyzed both the positive and negative effects of cyberloafing on student performance, finding that cyberloafing causes harmful interference to students in the classroom. However, a moderate amount of cyberloafing out of the classroom can have a positive impact on student performance by offering a means for relaxation (Wu et al. 2018).

\section{Future research directions}

The research on cyberloafing has progressed from early literature that defined the phenomenon, to articulating how people cyberloaf, to looking at why they do it, the benefits and consequences of engaging in it, mechanisms aimed to control it, and cyberloafing in different domains. The most recent branches in figures 6 and 7 look at the effects of cyberloafing on student performance (Wu et al., 2018), smartphone addiction and cyberloafing amongst students (Gokcearslan et al., 2018), and student attitudes and cyberloafing in classrooms (Yilmaz and Yurdugül, 2018). Future research should extend these streams. Wu et al. (2018) recommend that their study can be extended by longitudinal studies that track student performance over time. Gokcearslan et al. (2018) recommend that their study be extended by collecting data from a wide range of students with varying demographics. Yilmaz and Yurdugül (2018) also recommend that their study can be extended by exploring individual differences, including differences in cognitive characteristics, self-efficacy, introversion, et cetera. All three of these studies suggest that future research use more direct measures of cyberloafing. These studies, and the majority of cyberloafing research, tend to use indirect measures such as questionnaires to assess cyberloafing behavior.

The literature would also benefit from more research into the mental health consequences of cyberloafing. Recent research has found that cyberloafing can help employees cope with stress (Stoddart, 2016), but it also consumes employees' cognitive resources (Windeler, Chudoba, and Sundrup, 2017). Research should look at the point in which cyberloafing ceases to become a positive or negative activity and starts to have paradoxical mental health effects on employees or students. A recent study by Wu et al. (2020) demonstrates that social cyberloafing can have both positive and negative effects on employee mental health.

Much of the early research on cyberloafing was performed before mobile Internet devices became as prevalent as they are today. It would be interesting to see people's 
reactions to the changing domain. For example, literature has shown that individuals are more likely to cyberloaf when they have access and privacy (Ugrin, Pearson, and Odom, 2007); mobile devices create nearly unlimited access and privacy.

Cyberloafing may be affected by differences across cultures as individuals from different countries may be more or less inclined to use Internet resources for personal purposes when at work or school. Researchers may find models like the Hofstede Model of Cultural Dimensions (Hofstede, Hofstede, and Minkov, 2010) useful for identifying facets of various cultures that might lead to more or less cyberloafing in a particular country. Knowledge about the relationship between culture and cyberloafing could be useful for managers at multi-national corporations with offices and employees all over the world.

Cyberloafing literature would benefit from a better grounding in psychology theory and the integration of various theories. Various aspects of cyberloafing could be explained by theories like Prospect Theory, the Theory of Planned Behavior, Rational Choice Theory, Low Self-Control Theory, Organizational Justice Theory, General Deterrence Theory, and more. An integrated theory that brings the relevant aspects of these theories into one model would be groundbreaking.

\section{Limitations and Conclusions}

This study examines 116 high-quality papers on cyberloafing behavior indexed by SSCI and SCIE in the WOS database. We used bibliometric analysis to quantitatively analyze the cooperation network, citation network, and main path for more than 20 years of research on cyberloafing. We map the cooperation network, citation chronology and main path of cyberloafing research from 1997 to 2019, and reached the following conclusions. First, research interest in the field of cyberloafing is continuing to rise and is currently in a burgeoning stage. However, a complete theoretical model of cyberloafing has not been formed, and research interest in this field will continue to rise in the future. There are many scholars currently engaged in the research of cyberloafing, but the most influential authors are Lim, PabloZoghbi-Manrique-de-Lara, Anandarajan, and O'Neill. Although there is some cooperation among productive authors, in general, the degree of cooperation is low, and the level of cooperation between scholars across countries could be improved.

Second, the findings show that the United States, China, the United Kingdom, and Australia have a large number of publications and are at the core of the field of cyberloafing. The United States has the most publications, and China ranks second. However, there is still a significant gap between China and the United States.

Third, up to now, the most influential institutions engaged in cyberloafing research include the National
University of Singapore, Drexel University, Las Palmas University, Illinois State University, and Southern Illinois University Carbondale. There is a limited amount of connection between these active institutions, but overall, the institutions' cooperation network density is low, and the cooperative relationship is not close-knit. The existing cooperative research is limited to a few core networks, such as the cooperation network centered on Drexel University, St. Joseph University, and the University of Illinois.

Fourth, by analyzing the citation chronology and the main path of the cyberloafing research network, we conclude that cyberloafing research has evolved through three stages, the emergent stage, the exploration stage, and the burgeoning stage. The research topic has developed from concept definition and measurement, to antecedents and outcomes. Further, the research object has shifted from organizational employees to both employees and students in educational settings. Recent research has begun to focus on the positive effects of cyberloafing on individuals and organizations. However, research in this direction has been controversial, shifting from focusing on the negative effects and the assumption the cyberloafing is inherently bad.

This study makes several contributions to cyberloafing literature. First, this is the first study to rely on bibliometric and visualization techniques to map the development of cyberloafing research. This quantitative methodology can reduce potential biases due to human subjectivity. Second, this study determines influential authors, countries, and institutions in the cyberloafing research and reveals the density and degree of cooperation among authors, countries, and institutions. Third, by conducting a main path analysis, we identify 16 important papers playing critical roles in the development of cyberloafing research. We find that cyberloafing research has evolved through three stages, the emergent, exploration, and burgeoning stages. This finding extends past literature reviews on cyberloafing (Mercado et al., 2017) by shifting to an evolutionary perspective.

This study has a few limitations that are important to mention. First, our analysis covers a selected set of high-quality SCIE and SSCI journals in the WOS database. We assume that these publication sources can reasonably represent cyberloafing research. However, the WOS database cannot guarantee the coverage of all possible cyberloafing publications, which means that we might have missed some papers, particularly those published at conferences. Second, this study divides the development process of cyberloafing research into three stages according to the number of papers published each year and the results of the citation network and main path analysis. That is, the bibliometric approach is not entirely objective, and some amount of human judgment is needed to make the results meaningful. We also notice that it is impossible and sometimes undesirable to completely eliminate human subjectivity from scientific research. Future research is needed to 
develop meaningful procedures to keep a suitable balance between objectivity and subjectivity in conducting literature reviews.

\section{Acknowledgement}

This research was funded by the Humanity and Social Science Major Foundation of Education Committee of Anhui province (Grant No. SK2019ZD07) and the Natural Science Foundation of Anhui Province (Grant No. 1908085MG238 and 1908085QG301).

\section{Literature}

Akbulut, Y., Dönmez, O., \& Dursun, Ö.Ö. (2017). Cyberloafing and social desirability bias among students and employees. Computers in Human Behavior, 72, 87-95. https://doi.org/10.1016/j.chb.2017.02.043

Akbulut, Y., Dursun, Ö.Ö., Dönmez, O., \& Şahin, Y.L. (2016). In search of a measure to investigate cyberloafing in educational settings. Computers in Human Behavior, 55, 616-625.

https://doi.org/10.1016/j.chb.2015.11.002

Anandarajan, M. (2002). Internet Abuse in the Workplace. Communications of the ACM, 45(1), 53-54.

Andreassen, C.S., Torsheim, T., \& Pallesen, S. (2014). Predictors of Use of Social Network Sites at Work - A Specific Type of Cyberloafing. Journal of Computermediated Communication, 19(4), 906-921. https://doi. org/10.1111/jcc4.12085

Batagelj, V. (2003). Efficient algorithms for citation network analysis. In: http://arxiv.org/abs/cs.DL/0309023

Batagelj, V., \& Mrvar, A. (2004). Pajek - Analysis and Visualization of Large Networks. In: Jünger M., Mutzel P. (eds) Graph Drawing Software. Mathematics and Visualization. Springer, Berlin, Heidelberg. https://doi.org/10.1007/978-3-642-18638-7_4

Blanchard, A.L., \& Henle, C.A. (2008). Correlates of different forms of cyberloafing: The role of norms and external locus of control. Computers in Human Behavior, 24(3), 1067-1084. https://doi.org/10.1016/j. chb.2007.03.008

Block, W. (2001). Cyberslacking, Business Ethics and Managerial Economics. Journal of Business Ethics, 33(3), 225-231. https://doi.org/10.1023/A:1012002902693

Coker, B.L.S. (2013). Workplace Internet Leisure Browsing. Human Performance, 26(2), 114-125. https://doi. org $/ 10.1080 / 08959285.2013 .765878$

Davis, R.A., Flett, G.L., \& Besser, A. (2002). Validation of a new scale for measuring problematic internet use: implications for pre-employment screening. $C y$ berPsychology \& Behavior, 5(4), 331-345. https://doi. org $/ 10.1089 / 109493102760275581$

Freeman, L.C. (1977). A Set of Measures of Centrality Based on Betweenness. Sociometry, 40(1), 35-41. https://doi.org/10.2307/3033543

Gökçearslan, Ş., Uluyol, Ç. \& Şahin, S. (2018). Smartphone addiction, cyberloafing, stress and social support among university students: A path analysis. Children and Youth Services Review, 91, 47-54. https://doi. org/10.1016/j.childyouth.2018.05.036

Garrett, R.K., \& Danziger, J.N. (2008). On cyberslacking: workplace status and personal internet use at work. CyberPsychology \& Behavior, 11(3), 287-292. https:// doi.org/10.1089/cpb.2007.0146

Garrett, R.K., \& Danziger, J.N. (2010). Disaffection or expected outcomes: Understanding personal Internet use during work. Journal of Computer-Mediated Communication, 13(4), 937-958. https://doi.org/10.1111/ j.1083-6101.2008.00425.x

Greengard, S. (2000). The high cost of cyberslacking. Workforce, 79(12), 22-24. https://www.workforce. com/2000/12/01/the-highcost-of-cyberslacking/

Griffiths, M.D. (2011). Internet abuse in the workplace Issues and concerns for employers and employment counselors. Journal of Employment Counseling, 40(2), 87-96. https://doi.org/10.1002/j.2161-1920.2003.tb00859.x

Heflin, H., Shewmaker, J., \& Nguyen, J. (2017). Impact of mobile technology on student attitudes, engagement, and learning. Computers \& Education, 107, 91-99. https://doi.org/10.1016/j.compedu.2017.01.006

Henle, C.A., \& Blanchard, A.L. (2008). The interaction of work stressors and organizational sanctions on cyberloafing. Journal of Managerial Issues, 20(3), 383-400. https://www.jstor.org/stable/40604617

Hofstede, G., Hofstede, G. J. \& Minkov, M. (2010). Cultures and Organizations: Software of the Mind (Rev. 3rd ed.). New York: McGraw-Hill.

Jia H , Jai, .R., \& Karau S. (2013). Cyberloafing and Personality: The Impact of the Big Five Traits and Workplace Situational Factors. Journal of Leadership \& Organizational Studies, 20, 358-365. https://doi. org/10.1177/1548051813488208

Jia, R., \& Jia, H. (2015). An Individual Trait-based Investigation of Employee Cyberloafing. Journal of Information Technology Management, 26(1), 58-71.

Jia, Y., Wang, N., \& Ge, S. (2018). Business-IT Alignment Literature Review: A Bibliometric Analysis. Information Resources Management Journal, 31(3), 34-53. https://doi.org/10.4018/IRMJ.2018070103

Kamins, A. (1995). Cyber-Loafing: does employee time online add up to net losses? New York Daily News, July.

König, C.J., \& Guardia, M.E.C.D.L. (2014). Exploring the positive side of personal internet use at work: Does it help in managing the border between work and nonwork? Computers in Human Behavior, 30(30), 355360. https://doi.org/10.1016/j.chb.2013.09.021

Lavoie, J.A.A., \& Pychyl, T.A. (2001). Cyberslacking and the Procrastination Superhighway: A Web-Based Survey of Online Procrastination, Attitudes, and Emotion. Social Science Computer Review, 19(4), 431-444. 
https://doi.org/10.1177/089443930101900403

Li, J., \& Chen, C. (2017). CiteSpace: Text Mining and Visualization in Scientific Literature. Beijing, Capital University of Economics and Business Press.

Liberman, B., Seidman, G., Mckenna, K.Y.A., \& Buffardi, L.E. (2011). Employee job attitudes and organizational characteristics as predictors of cyberloafing. Computers in Human Behavior, 27(6), 2192-2199. https://doi. org/10.1016/j.chb.2011.06.015

Lim, V.K.G. (2002). The IT Way of Loafing on the Job: Cyberloafing, Neutralizing and Organizational Justice. Journal of Organizational Behavior, 23(5), 675-694. https://doi.org/10.1002/job.161

Mahatanankoon, P., Anandarajan, M., \& Igbaria, M. (2004). Development of a measure of personal web usage in the workplace. CyberPsychology \& Behavior, 7(1), 93104. https://doi.org/10.1089/109493104322820165

Meijman, T.F., \& Mulder, G. (1998). Psychological Aspects of Workload. In P.J.D. Drenth, H. Thierry and C.J. de Wolff (Eds.), New Handbook of Work \& Organizational Psychology (2nd ed.) (pp. 5-33). Hove, England: Psychology Press/Erlbaum (UK) Taylor \& Francis.

Mercado, B.K., Giordano, C., \& Dilchert, S. (2017). A meta-analytic investigation of cyberloafing. Career Development International, 22(1), 546-564. https://doi. org/10.1108/CDI-08-2017-0142

Moody, G.D., \& Siponen, M. (2013). Using the theory of interpersonal behavior to explain non-work- related personal use of the Internet at work. Information \& Management, 50(6), 322-335. https://doi. org/10.1016/j.im.2013.04.005

O’Neill, T.A., Hambley, L.A., \& Bercovich, A. (2014). Prediction of cyberslacking when employees are working away from the office. Computers in Human Behavior, 34(4), 291-298. https://doi.org/10.1016/j. chb.2014.02.015

Oravec, J.A. (2002). Constructive approaches to internet recreation in the workplace. Communications of the ACM, 45(1), 60-63. https://doi. org/10.1145/502269.502298

Phillips, J.G. (2006). The psychology of Internet use and misuse. M. Anandarajan, T. Thompson, C. Simmers (Eds.), The Internet and workplace transformation, Sharpe, Armonk (2006), pp. 41-62.

Polito, A. (1997). Cyberloafing can be curbed. Workforce, $76,18$.

Price, D.J. de S. (1963). Little Science, Big Science. New York: Columbia University Press.

Reinecke, L. (2009). Games at work: the recreational use of computer games during working hours. CyberPsychology \& Behavior, 12(4), 461-465. https://doi. org $/ 10.1089 / \mathrm{cpb} .2009 .0010$

Sheikh, A., Atashgah, M.S., \& Adibzadegan, M. (2015). The antecedents of cyberloafing: A case study in an Iranian copper industry. Computers in Human Behavior, 51, 172-179. https://doi.org/10.1016/j. chb.2015.04.042

Stoddart, S.R. (2016). The Impact Of Cyberloafing And Mindfulness On Employee Burnout. Wayne State University. Retrieved from: https://digitalcommons. wayne.edu/cgi/viewcontent.cgi?referer=https://scholar.google.com $/ \&$ httpsredir $=1 \&$ article $=2486 \&$ contex$\mathrm{t}=\mathrm{oa}$ dissertations

Syrek, C.J., Kühnel, J., Vahlehinz, T., \& Bloom, J.D.J.W. (2017). Share, like, twitter, and connect: Ecological momentary assessment to examine the relationship between non-work social media use at work and work engagement. Work \& Stress, 32(3), 209-227. https:// doi.org/10.1080/02678373.2017.1367736

Ugrin, J.C., \& Pearson, J.M. 2013. The effects of sanctions and stigmas on cyberloafing. Computers in Human Behavior, 29(3), 812-820. https://doi.org/10.1016/j. chb.2012.11.005

Ugrin, J. C., Pearson, J. M., \& Odom, M. D. 2007. Profiling cyber-slackers in the workplace: Demographic, cultural, and workplace factors. Journal of Internet Commerce, 6, 75-89. https://doi.org/10.1300/ $\mathrm{J} 179 \mathrm{v} 06 \mathrm{n} 03 \quad 04$

Vitak, J., Crouse, J., \& Larose, R. (2011). Personal Internet use at work: Understanding cyberslacking. Computers in Human Behavior, 27(5), 1751-1759. https://doi. org/10.1016/j.chb.2011.03.002

Windeler, J. B., Chudoba, K. M., \& Sundrup, R. Z. (2017). Getting away from them all: Managing exhaustion from social interaction with telework. Journal of Organizational Behavior, 38(7), 977-995. https://doi. org/10.1002/job.2176

Wu, J., Mei, W., \& Ugrin, J.C. (2018). Student Cyberloafing In and Out of the Classroom in China and the Relationship with Student Performance. Cyberpsychology $\square$ Behavior $\square$ and Social Networking, 21(3), 199-204. https://doi.org/10.1089/cyber.2017.0397

Wu, J., Mei, W., Liu, L., \& Ugrin, J.C. (2020). The bright and dark sides of social cyberloafing: Effects on employee mental health in China, Journal of Business Research, 112, 56-64. https://doi.org/10.1016/j.jbusres.2020.02.043

Yılmaz, R., \& Yurdugül, H. (2018). Cyberloafing in IT classrooms: exploring the role of the psycho-social environment in the classroom, attitude to computers and computing courses, motivation and learning strategies. Journal of Computing in Higher Education (4), 1-23. https://doi.org/10.1007/s12528-018-9184-2

Zhang, H., Zhao, H., Liu, J., Xu, Y., \& Lu, H. (2015). The dampening effect of employees' future orientation on cyberloafing behaviors: the mediating role of self-control. Frontiers in Psychology, 6, Article 1482. https:// doi.org/10.3389/fpsyg.2015.01482 
Jin-Nan $\mathbf{W u}$ is a professor of MIS and the Dean of the School of Business at Anhui University of Technology, China. His research focuses on cyberloafing, e-commerce, online consumer behavior, and social and managerial issues of IT. Dr. Wu has published more than 30 articles in Cyberpsychology Behavior and Social Networking, Information Technology \& People, Industrial Management \& Data Systems, Electronic Commerce Research, Journal of Business Research, and others.

Mengmeng Song is a postgraduate of Cyberpsychology at Anhui University of Technology, China. Her research focuses on social contagion of cyberloafing.

Joseph C. Ugrin is the Deloitte Professor of Accounting and Head of the Department of Accounting at the University of Northern lowa, USA. He primarily researches behavioral issues in accounting and information systems and has published research in the area of information systems and technology in journals such as Computers in Human Behavior, the Journal of
Business Research, Information Technology \& People, Communications of the Association for Information Systems, the Journal of Information Systems Education and others.

Lin Liu is a lecturer of Human-computer interaction at Anhui University of Technology, China. Her research focuses on human-computer interaction, online consumer behavior, and social media. She has published more than 10 articles in Information Technology \& People, Industrial Management \& Data Systems, Journal of Business Research, Frontiers in Psychology, Journal of Electronic Commerce in Organizations and some MIS conferences such as PACIS and WHICEB.

Tingting Zhu is a lecturer of organizational behavior at Anhui University of Technology, China. Her research focuses on ethics and information technology, and social media use in workplace. 